\title{
Animal Supply and Logistics Activities of Abattoir Chain in Developing Countries: The Case of Kumasi Abattoir, Ghana
}

\author{
Samuel Frimpong ${ }^{1}$, Girma Gebresenbet ${ }^{2 *}$, Techane Bosona ${ }^{2}$, Emanuel Bobobee ${ }^{1}$, Elias Aklaku ${ }^{1}$, \\ Ibrahim Hamdu ${ }^{1}$ \\ ${ }^{1}$ Kwame Nkrumah University of Science and Technology, Kumasi, Ghana; ${ }^{2}$ Swedish University of Agricultural Sciences, Uppsala, Sweden. \\ Email: "girma.gebresenbet@slu.se
}

Received November $3^{\text {rd }}, 2011$; revised December $6^{\text {th }}, 2011$; accepted December $15^{\text {th }}, 2011$

\begin{abstract}
The concern about the welfare of livestock during transport is increasing as animal production and transport for slaughter and breeding is increasing. The main objective of this study was to investigate the characteristics of animal supply and activities in slaughter chain in the Kumasi abattoir, Ghana. The main stakeholders were indentified and interviewed. Based on the data and information gathered (through interview, field measurements, observation and activity registration), the main characteristics of the animal supply and activities in the abattoir chain were mapped out. The study indicated that the animals were sourced from inside and outside Ghana. The purchased animals were first sent to a local collection centre before onward transportation to the Cattle Market in the Kumasi city, where the animals should stay until sold and taken to abattoir to be slaughtered. The study indicated that inhuman way of animal handling, incidence of non-ambulation, sickness and death of animals were common during transport as well as inside Kumasi cattle market. The slaughtering procedures and meat distribution to the butcheries lacked good hygienic conditions compromising meat safety and quality. These issues of animal welfare and meat safety and quality should get attention and improvements must be planned.
\end{abstract}

Keywords: Ghana; Kumasi Abattoir; Animal Supply Chain; Animal Handling; Animal Welfare; Meat Distribution

\section{Introduction}

During the past half century, animal production has increased in developing countries [1] and transport of animals for slaughter and breeding is increasing due to the global marketing system and structural adjustments [2]. Pre-transport conditioning, time in transit, distance travelled, environmental conditions, and lairage at the slaughterhouse are all components of transportation that may negatively affect stress levels and diminish the economic value of the animals and the meat products [3].

There are growing concerns, about the welfare of livestock during transport and handling. Vehicle design, stocking density on vehicles, journey duration, time of feeding, mortality and weather conditions, among others are factors that affect slaughter animals' welfare [4]. According to Gebresenbet [5], animal welfare during transport could be improved by these two strategic alternatives: 1) minimising stress inducing factors through improving animal logistics system and handling methods (improve handling, facilities for loading and unloading, driving perfor-

\footnotetext{
"Corresponding author.
}

mance, optimised activities at the abattoir); 2) minimising or avoiding transport, by encouraging small-scale local abattoir or developing a mobile or semi-mobile abattoir. The logistics chain of an abattoir may comprise activities from loading of animals at farms, transport from farm to abattoir, unloading of animals at the abattoir, and operations in the slaughter chain from the lairage box to cooling rooms for carcasses [6].

The abattoir system in the developed world is quite different from that in the developing world. While the abattoir system in the developed world provides services that are geared towards meat quality, most of the abattoir systems in the developing countries, including Kumasi abattoir in Ghana, provide services for butchers focusing on the quantity of meat required, without due consideration of meat safety and quality. Cattle destined for slaughter at the Kumasi Abattoir are transported from Farms within Ghana and from neighboring countries. The movement of the animals from the farm or cattle market to the abattoir premises when animals are led to the lairage and subsequently into the abattoir. This process is a spectacle to behold; and cruel handling of animals to the highest 
degree is common in the slaughter animal supply chain. There is insufficient information on animal handling and related animal welfare problems that can be used as basis to develop animal welfare policies in Ghana, in relation to animal transport and abattoir logistics services.

The main objective of this study was to study the characteristics of animal supply to the Kumasi Abattoir and activities in slaughter chain in the abattoir. The specific objectives were to:

1) Identify the main source of slaughter animals and main stakeholders involved in animal supply chain;

2) Map out the activities in the animal transport and abattoir logistics chains;

3) Investigate the meat distribution from the abattoir to butcheries in Kumasi city.

It was intended to prepare valuable scientific information that could be used as basis for further studies of animal transport and its impact on animal welfare, meat safety and quality as well as economic issues in Ghana and other developing countries.

This paper is structured as follows. In Section 2, the methodology is described. In Section 3, results are presented while discussion of the findings has been presented in Section 4. In Section 5 conclusion is presented.

\section{Methodology}

\subsection{Study Area}

Based on some initial observations regarding inhumane animal treatment during transport to Kumasi abattoir, this study was conducted in Ghana. Kumasi abattoir is one of abattoirs in developing countries to which animals are supplied from farms within and outside a country after a long journey. Cattle destined for slaughter at the Kumasi Abattoir are transported from different regions within Ghana such as Yeji in Brong Ahafo and the northern regions of Ghana and from neighboring countries like Burkina Faso, Mali and Niger (see Figure 1).

The Kumasi Abattoir is located at $6^{\circ} 39^{\prime} 36.6^{\prime \prime N}$ Latitude and $1^{\circ} 36^{\prime} 15.4^{\prime \prime} \mathrm{W}$ Longitude, in the Kumasi city of Ghana. The butchers where the meat from the Kumasi abattoir is distributed are located within the Kumasi city (see Figure 1).

\subsection{Kumasi Abattoir and Slaughter Animals}

The Kumasi Abattoir Company Limited was established in 1997 with grants from the Government of Ghana and the Canadian International Development Agency (CIDA) and commenced its operations in 1998. There is a cattle market at the abattoir premises about $150 \mathrm{~m}$ away from the abattoir. At the cattle market, there are kraals which are used to house the animals while they are being sold. There is also a holding pen for the cattle which are des-

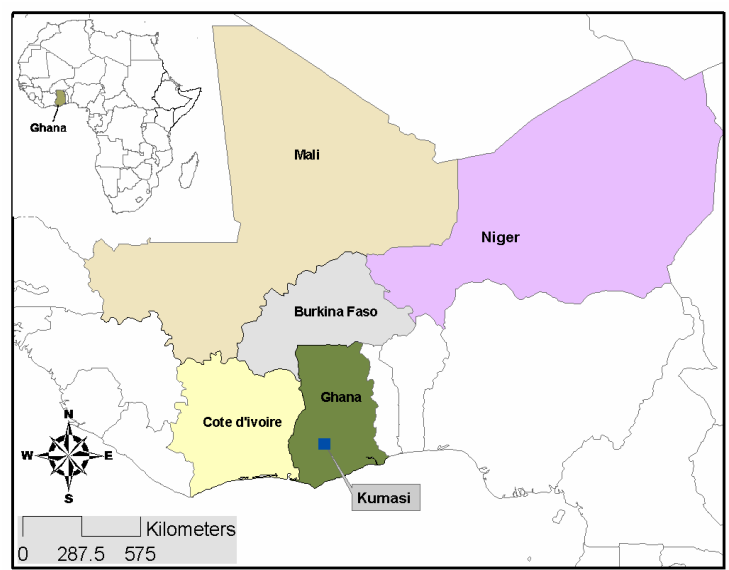

(a) Study area

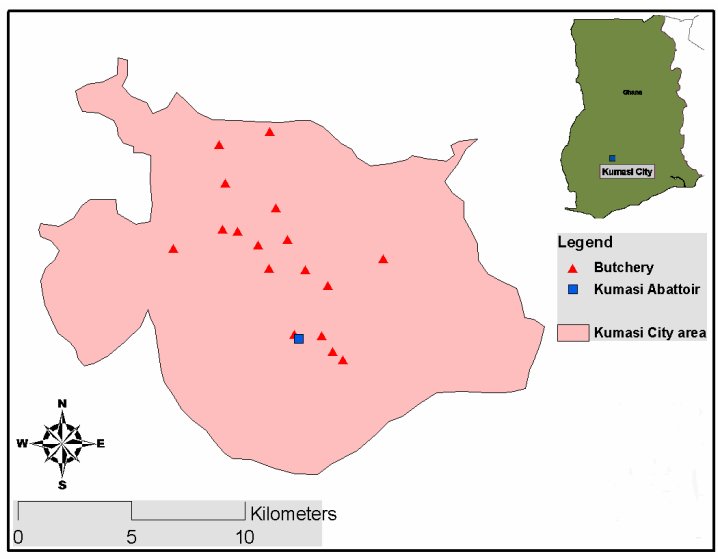

(b) Locations of butcheries

Figure 1. Study area and locations of Kumasi Abattoir. (a) Countries from where animals were sourced; (b) The 17 recognized butcheries and Kumasi abattoir on the map of Kumasi City.

tined for slaughter. The holding pen which is about $10 \mathrm{~m}$ away from the slaughterhouse is used to keep cattle overnight until the next morning when they are slaughtered. There is a lairage which is supposed to be used for resting of animals for sometime before slaughter. There is a defunct waste treatment plant and an abandoned fish pond about $100 \mathrm{~m}$ away from the slaughterhouse.

Although, the Kumasi abattoir slaughters animals like cattle, pigs, sheep and goats for processing and packaging for the targeted Ghanaian markets, the slaughter animals considered in this study were only cattle. The original daily slaughtering capacity of the Abattoir was 200 cattle, 100 pigs, and 250 sheep and goats. In addition to this, the production facility of the abattoir has been redesigned to enable the Company slaughter up to 400 cattle daily. This was achieved by converting one of the slaughter lines meant for the slaughter of sheep and goats into another cattle line and developing a singeing platform. 


\subsection{Data Collection}

In this study, data was collected via interviews, field measurements and observations of activities during animal transport and slaughter operations. For better planning of field work and proper design of questionnaires, preceding exploratory visits and interviews with key people at the abattoir were made. Data on the sources of slaughter animals, transport distance, means of transport, animal handling condition during transport, locations of butcheries, means of transporting meat and problems (related to management of animal supply and slaughter chains in the abattoir) were gathered.

\subsubsection{Interview with Stakeholders}

The major stakeholders identified in this animal supply chain include farmers, merchants (who go and buy cattle from the origin and transport them to the Kumasi Cattle Market), landlords (who are responsible for receiving and selling of cattle at Kumasi cattle market), butchers (owners of meat shops), and cowboys (cattle handlers). Face-to-face interviews were conducted with 50 merchants, 32 landlords and 43 butchers. The merchants were interviewed to find out, the number and the origin of the cattle and the effect of transport on the animal welfare during the long journey from the animal farm to the Kumasi Cattle Market. The landlords were interviewed to find out the health condition of animals before they were bought and their main problems within the supply chain. The butchers were interviewed to find out about their operations and the problems they encountered in the process of buying animals; getting slaughter service and selling meat.

\subsubsection{Field Measurements and Observation}

Field measurements were carried out to gather data on the non-ambulatory cattle and to register (using a handheld Geographical Positioning System) the geographic coordinates of the locations of the recognized butcheries in the Kumasi city. The coordinates (including the coordinates of Kumasi abattoir) were later used to indicate the locations of recognized meat shops on map in relation to the location of Kumasi abattoir, using ArcView 3.2. Non-ambulatory animals were counted for one week. The ratio of the total number of non-ambulatory animals to the total number of animals moved from the cattle market into the abattoir for slaughter was determined and expressed as a percentage. The activities in the abattoir were also observed and registered.

\section{Results}

\subsection{Characteristics of Stakeholders}

Table 1 presents the summary of the results of interviews
Table 1. Summarized result of interview with stakeholders.

\begin{tabular}{lcccc}
\hline Stakeholder & $\begin{array}{c}\text { Number of } \\
\text { interview } \\
\text { participants }\end{array}$ & $\begin{array}{c}\text { Age range } \\
\text { [year] }\end{array}$ & $\begin{array}{c}\text { Average age } \\
\text { [year] }\end{array}$ & $\begin{array}{c}\text { Literacy } \\
{[\%]}\end{array}$ \\
\hline Merchants & 50 & $23-68$ & 39 & 34 \\
Landlords & 32 & $27-95$ & 45 & 63 \\
Butchers & 43 & $29-64$ & 43 & 44 \\
\hline
\end{tabular}

conducted with each category of stakeholders (merchants, landlords and butchers). The butchers recognized by authorities of Kumasi Abattoir belong to about 6 different associations with different number of members ranging from 2 to 15 butchers.

The average age of the merchants interviewed was 39.2 years, ranging from $23-68$ years. This confirmed that quite like the butchers and landlords, the work of the merchants is largely done by the active youth. The average age of landlords was 45 years, while that of butchers was 43.

The butchers' work was done by the youngest people among the three groups of stakholders. The educational backgrounds of the merchants, landlords and butchers indicated that $34 \%, 63 \%$ and $44 \%$ were literates respectively (see Table 1). This proves that majority of the merchants and butchers lack basic education, while, relatively, more landlords have basic education. Figure 2 presents the linkage of stakeholders involved in the animal supply chain.

\subsection{Sources of Slaughter Animals}

Most of the slaughter animals were bought from markets inside the Ghana, although animals were also bought from neighboring countries (see Table 2 and Figure 3). About $58 \%$ of the merchants purchased their cattle only from Ghana while $8 \%$ of them purchased their cattle only from Burkina Faso. The remaining merchants (34\%) purchased from two or more different countries.

The merchants could purchase from individual farmers, regional markets or big markets. $40 \%$ of the merchants purchased their cattle from individual farmers; $10 \%$ of them purchased from both individual farmers and big markets; $2 \%$ of them purchased from both individual farmers and regional markets; and $8 \%$ of them purchased from all three points of purchase. After the merchants had purchased their respective animals from the various points of purchase, they transported those animals to a collection centre (an average distance of $38.14 \mathrm{~km}$ ) before onward transport to Kumasi.

\subsection{Handling, Loading and Unloading of Animals during Transport to Kumasi}

The means of transport were walking, use of vehicles, and 


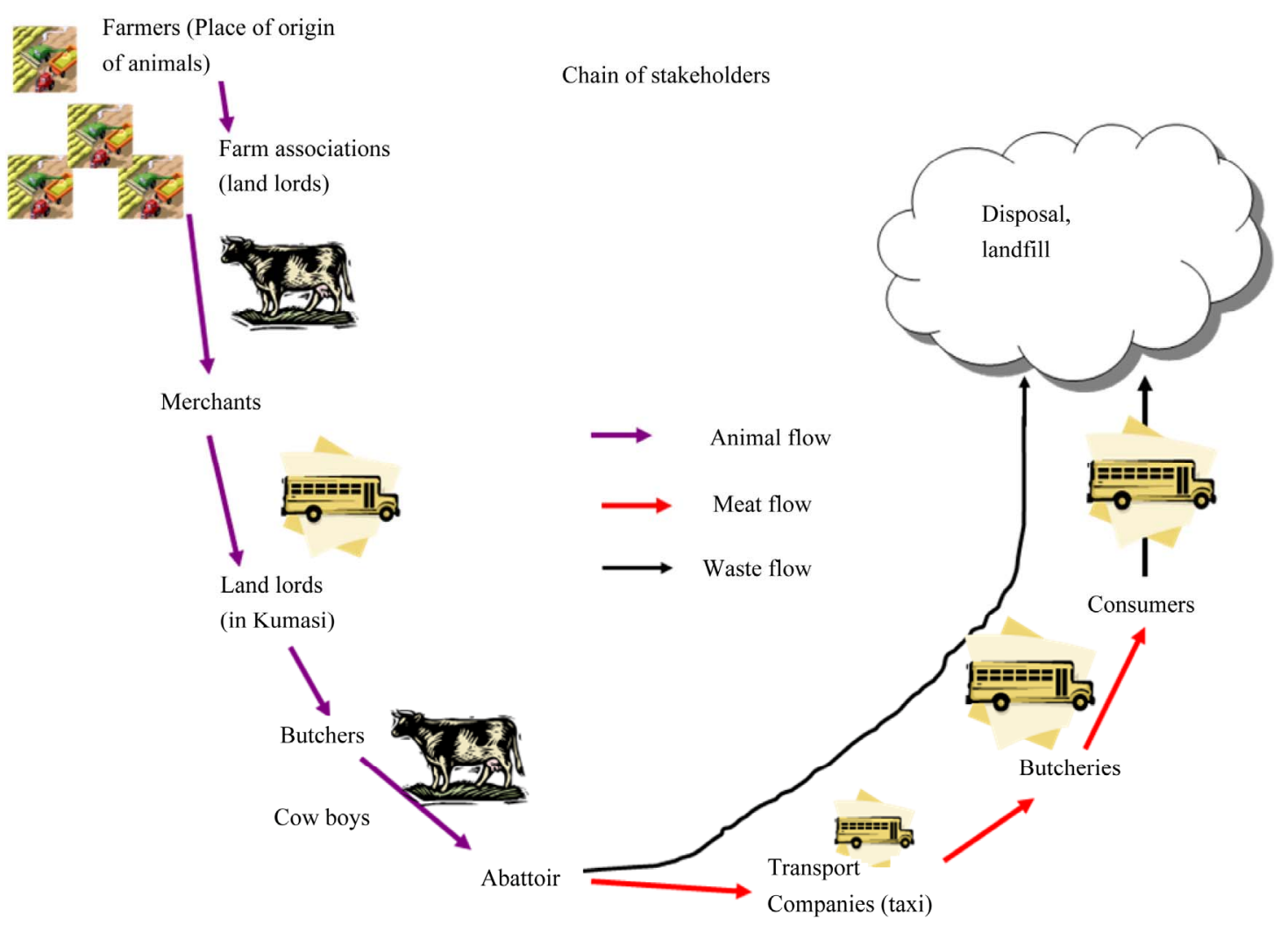

Figure 2. Linkage of stakeholders involved in the animal supply chain.

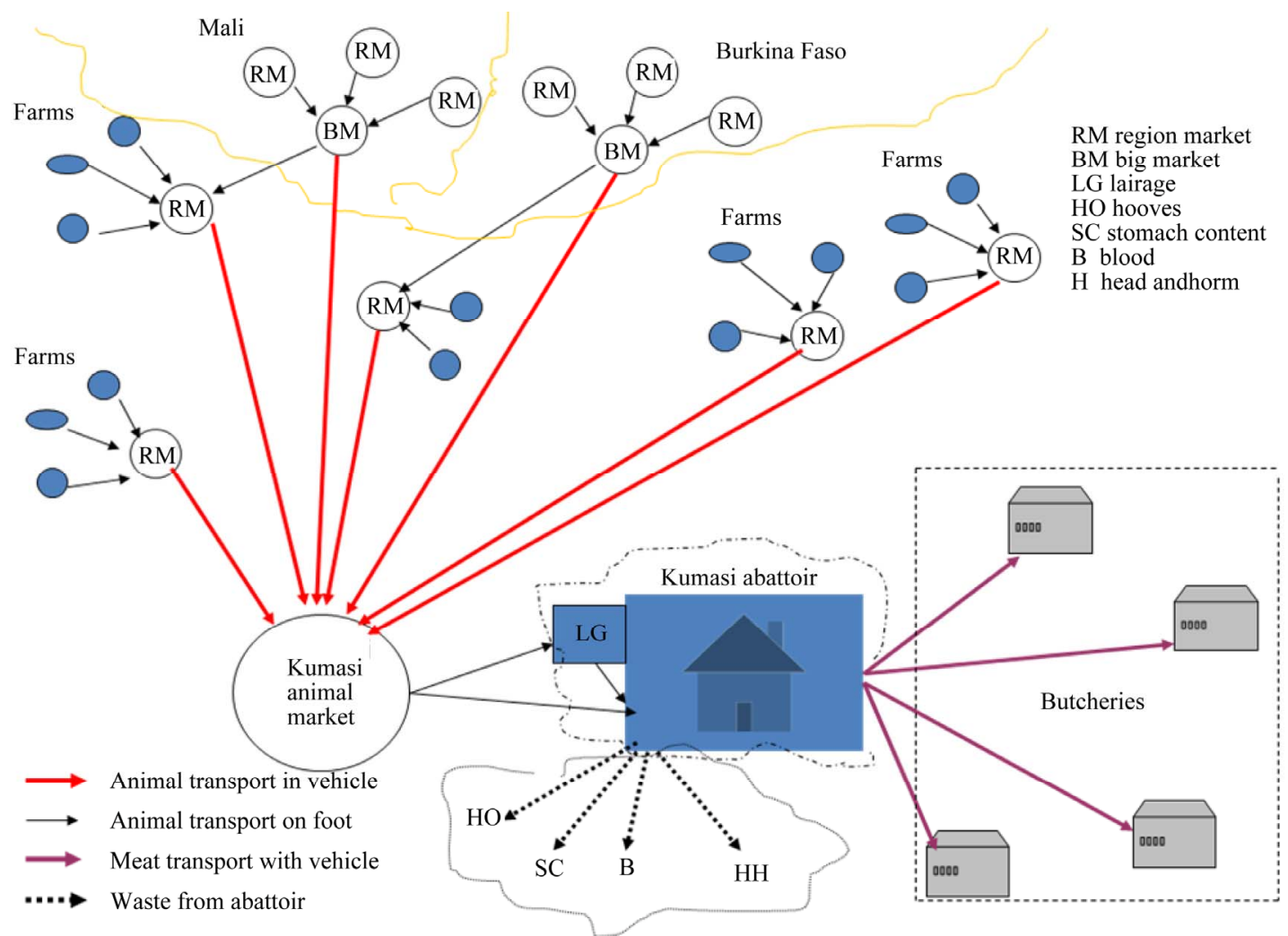

Figure 3. The flow of slaughter animals and means of transport. 
Table 2. Origin of Slaughter animals and proportion of merchants supplying to Kumasi market.

\begin{tabular}{lc}
\hline Source of animal & Merchants (\%) \\
\hline Only Ghana & 58 \\
Only Burkina Faso & 8 \\
Burkina Faso and Ghana & 20 \\
Cote D'Ivoire and Ghana & 4 \\
Burkina Faso and Mali & 2 \\
Burkina Faso, Ghana and Mali & 2 \\
Burkina Faso, Cote D'Ivoire and Ghana & 4 \\
Burkina Faso, Cote D'Ivoire, Mali and Ghana & 2 \\
\hline
\end{tabular}

*Proportion of the 50 merchants participated in the interview.

use of boats. Twenty-four percent of the merchants reported that they transported purchased animals directly to Kumasi without sending them to collection centers. About $46 \%$ of the merchants walked their cattle to collection center while $14 \%$ of them used vehicles to transport their animals. In some cases (where there is water to be crossed) the merchants sat in canoes/boats while the cattle swam to cross water and then walked to the animal collection centers.

The merchants used vehicles in transporting purchased animals from the collection centre to Kumasi cattle market and the average number of animals a merchant purchased was 21.4 per trip. To transport animals from collection centers to Kumasi, it took on average about 37 hours. It took at most 8 hours to transport the animals from Yeji in Ghana, 24 hours from northern Ghana, 48 hours from Burkina Faso and Cote D'Ivoire, and 72 hours from Mali to Kumasi.

Long journey of cattle, especially without rest, affects the welfare of slaughter animals. In most cases the animals were lashed during loading and unloading. Most of the merchants $(82 \%)$ did not use rest stops for the animals on the journey to Kumasi. Out of the merchants who used rest stops, $66.7 \%$ used only 1 rest stop, $22.2 \%$ used only two rest stops and $11.1 \%$ used 3 rest stops. All the merchants interviewed did not protect their animals from bad weather and only $18 \%$ of the merchants provided food and water to their animals during transport to Kumasi Cattle market.

All interviewed merchants pointed out that there were instances where animals died during transport (see Table 3) to Kumasi and such carcasses were disposed of by throwing them away $(90 \%)$, burying $(2 \%)$, sending to the Kumasi Zoo (4\%) (to feed carnivorous animals), and giving out such carcasses to some security personnel at security checkpoints. Such deaths averaged 2 carcasses per merchant per trip. Ninety-eight percent of the merchants confirmed there were instances where some ani- mals became crippled or non-ambulatory during transportation to Kumasi i.e. 3 animals per merchants per trip.

\subsection{Animal Handling at Kumasi Cattle Market}

At the Kumasi cattle market, the number of animals received by landlords was 38 per truck, out of which about $2 \%$ were non-ambulatory animals and $2 \%$ were dead animals. The non-ambulatory animals were put out for sale and within a week, about 90 non-ambulatory cattle were taken to the abattoir for slaughter representing about $7 \%$ of the total number $(n=1260)$ of animals slaughtered within the week period. Such non-ambulatory cattle were drawn by carts from the market to abattoir. Concerning the dead animals, most of the carcasses were taken to the Kumasi Zoo for feeding carnivorous animals while the remaining carcasses were buried. The incidences of sickness and death of animals was observed at Kumasi market and most of (78.3\%) the landlords who experienced the sickness of animals offered treatment to their sick animals; about $13 \%$ of them sold out such animals; the remaining $8.7 \%$ of them slaughtered their sick animals. In most cases the costs of dead animals were covered by merchants even thought such costs were shared between the landlord and their merchant sometimes.

Most of the (78.1\%) of the interviewed landlords could sell their animals within a week, after arrival at Kumasi market. The animals were housed in kraals at the cattle market in the abattoir premises. There is no provision of shelter (as form of protection against bad weather) to animals at Kumasi cattle market. Some of the landlords offered food and water to their animals only on spot; some of them don't feed on spot but sent their cattle to pasture lands in the mornings and evenings for grazing; and other land lords used both means to feed their animals.

\subsection{Potential Buyers and Average Price of Slaughter Animals}

The potential buyers of the slaughter animals at Kumasi cattle market are the butchers and private individuals. Thirteen percent of the interviewed landlords could sell, on the average, no more than 5 animals per day, $84.4 \%$ of them could sell from 5 to 50 animals on average per day and $3.1 \%$ of them could sell more than 50 animals on the average per day. About $3 \%$ of the landlords could sell at average cost of GHC 500 (or less than this) per animal while the other $3 \%$ could sell at price more than GHC 1000 on average. About $93.8 \%$ of them could sell at GHC 750 on average.

All of the butchers bought their animals from Kumasi cattle market. About $97.7 \%$ of the interviewed butchers bought less than 5 animals per day per butcher while 
The Case of Kumasi Abattoir, Ghana

Table 3. Estimation of losses during transport to Kumasi cattle market.

\begin{tabular}{ccccc}
\hline Description & Per merchant & By all merchants & $\begin{array}{c}\text { Average total } \\
\text { revenue [GHC] }\end{array}$ & Remark \\
\hline $\begin{array}{c}\text { Number of animals brought to } \\
\text { Kumasi market per trip }\end{array}$ & 21.4 & 1070 & 802500.00 & $\begin{array}{c}\text { Income per trip if there } \\
\text { was no loss }\end{array}$ \\
$\begin{array}{c}\text { Incidence of non-ambulation } \\
\text { Incidence of death }\end{array}$ & 3 & 150 & 56250.00 & $7 \%$ loss \\
Total loss & 2 & 100 & 75000.00 & $9.4 \%$ loss \\
\end{tabular}

*Revenue estimated based on the average selling price ( $750 \mathrm{GHC}$ per healthy cattle) at Kumasi cattle market. For non-ambulatory cattle $375 \mathrm{GHC}$ was considered. The incidence of non-ambulation and death at Kumasi market was not included.

$2.3 \%$ bought 5 to 10 animals per day per butcher. Most of the butchers were willing to buy animals without much worry about the health status of the animals i.e. they bought non-ambulatory and sick animals. Most of the animals bought by the butchers were slaughtered within a day and less than 5 animals were slaughtered per day per butcher. About $97.7 \%$ of the butchers kept the bought animals for approximately one day before slaughter, $7 \%$ of them kept the animals for approximately 2 days and $2.3 \%$ of them kept animals for more than 2 days before slaughter. About $56 \%$ of the butchers interviewed did not provide food and water before slaughter, indicating that the majority of the butchers do not care about feeding the animals.

\subsection{Abattoir Activities}

The cowboys, paid by the butchers, were responsible for moving animals (destined for slaughter) from the cattle market into the abattoir. The activities within the abattoir logistics chain are mapped out in Figure 4. After the animals were delivered to abattoir, they were inspected and moved to lairage and prepared for stunning. Then slaughter activities from bleeding up to evisceration were carried out. Then packaging and cooling activities, starting from carcass inspection up to chilling were completed. Finally the meat was loaded for transport to butchers.

\subsection{Meat Distribution}

After the slaughtering process in the abattoir was completed, the meat was transported to butcheries. Although about 43 butchers were interviewed, the coordinates of only 17 butcheries were identified and their locations are as shown on the map of Kumasi (see Figure 1). Most of these 17 butchers are located north of the Kumasi abattoir. Ten of the butcheries were bigger in size than the rest but almost all of them were substandard in terms of facilities and hygiene.

All the butchers considered blood, faeces, hooves, and horns of the slaughtered cattle as waste while none of the butchers considered any visceral organ as waste. The responsibility of waste disposal was the duty of the $\mathrm{Ku}$ -

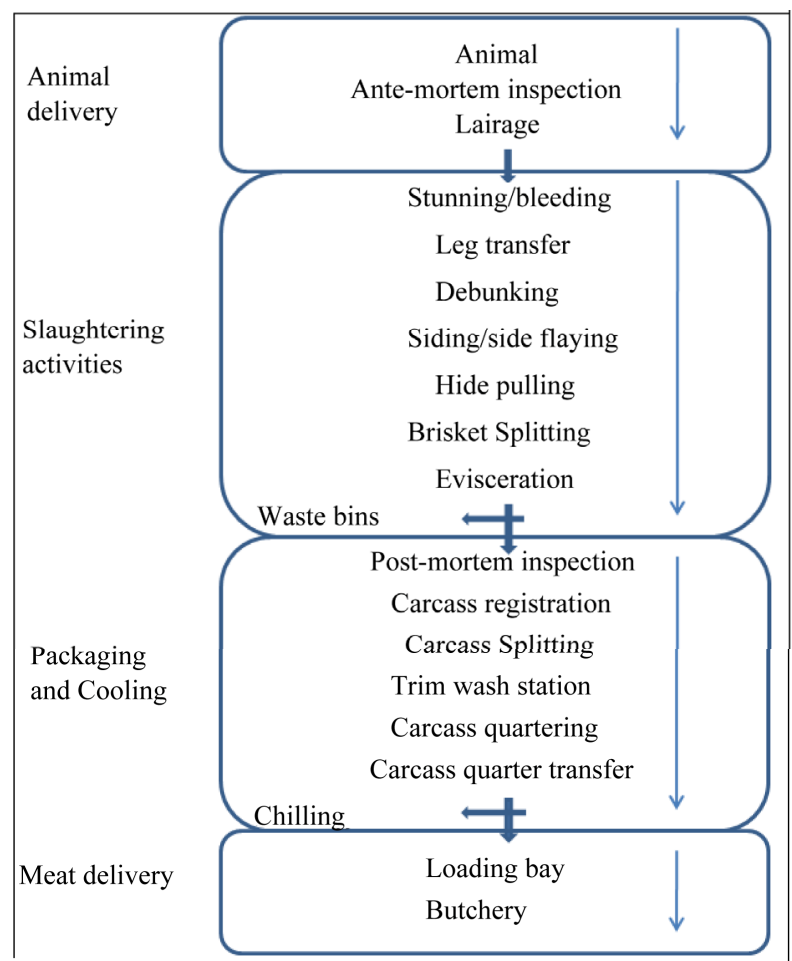

Figure 4. Activity flow in the Kumasi Abattoir.

masi Abattoir. The butchers are responsible for transporting the meat from the abattoir to their meat shops. It was revealed that none of the butchers used approved meat vans. About $44.2 \%$ of the butchers used only taxis, $7 \%$ used pick-ups, and $48.8 \%$ used either taxi or pick-up. As only about $33 \%$ of the butchers were able to sell all of their meat in a day, most of the remaining butchers used refrigeration to preserve the left-over meat.

\section{Discussion}

\subsection{Animal Transport Situation and Economic Loss}

In the animal supply chain of Kumasi abattoir, the slaughter animals were transported for long time up to 37 hours on average. This has negative implication for animal welfare. For example European regulation concerning 
animal welfare imposes that no animal should stay more than 8 hours on a vehicle without rest [7]. All the merchants interviewed confirmed that they do not offer any form of protection against unfavorable weather for their animals and this has a serious welfare implication. During transport and handling, animals might be exposed to unfavorable conditions such as food and water deprivation, unfavorable temperature or ventilation, aggressions and physical shocks which cause hunger and thirst, heat stress and pain. Such unfavorable conditions compromise also meat quality $[2,8]$.

This study revealed that the incidence of non-ambulation and death of animals were common due to overcrowding and falling on the truck (mostly as a result of poor driving behavior of drivers and poor road conditions), hunger, disease, and unfavorable weather the animals were exposed to. About $91 \%$ of the landlords confirmed that they received dead animals on arrival which indicated significant amount of economic loss during animal transport to the abattoir. The number of animals that died during transport or shortly after being delivered to an abattoir may be an indication of poor animals' welfare conditions during transport [9]. According to Reynolds [10], causes of down or non-ambulatory cattle probably vary by region, herd size and herd management and the major categories of causes for non-ambulatory cattle are injuries, infectious diseases and metabolic disorders.

In this study, the incidence of non-ambulatory cattle of $7 \%$ was recorded. This is high when compared with the result of some previous studies. Some researchers [11] recorded $1.1 \%$ incidence of non-ambulation while other researchers [12] recorded $0.04 \%$ and $0.38 \%$ incidences of non-ambulation in 2003 and 2004 respectively.

In this animal supply chain the incidence of whipping was confirmed. Whipping animals is known to have welfare and economic implications because when the animals are lashed it can lead to bruising which may have to be trimmed. These trimmings reduce the quality of the carcass and skin leading to economic loss. The economic loss due to the incidence of non-ambulation and animal death during transport from the origin to Kumasi cattle market was estimated to be about $16 \%$ of the expected income (see Table 3). On top of this, there are economic losses due to sickness and death of animals during their stay in the Kumasi cattle market.

\subsection{Management Problems in Animal Supply Chain of Kumasi Abattoir}

Pertaining to the problems encountered by the merchants in their work, all of them mentioned that unnecessary delays by security personnel at security check points, exorbitant charges by veterinary/quarantine officials for certifying animals as healthy or not, and financial con- straints were major problems. Robbery and fluctuations in the cedi rates to other currencies and poor road networks from Mali, Burkina Faso and Cote D'Ivoire were also mentioned as problems.

Among the problems encountered in the work of the landlords included financial aid, quick repayment of cost of animals bought on credit by butchers, regular supply of animals, relocation of the cattle market to places where there is abundant forage for animals to graze, maintenance of kraals at the cattle market, poor or insanitary conditions at the cattle market.

Some of the problems butchers encountered in their work, were financially constraints, indiscipline inside the abattoir, exorbitant extra charges aside cost of animals by landlords, patronage of foreign meat by consumers leading to poor daily sales, disunity among some butchers and landlords, and lack of capable official mouthpiece to articulate butchers' grievances despite the various associations they belonged to.

The loading and unloading procedures observed in this study were very poor and should be improved since such activities deteriorate the welfare of animals and reduce the economic benefits $[13,14]$. The drivers and animal handlers should be trained and the awareness of the stakeholders in this animal supply chain should be increased. A well educated handler can often move animals through novel situations efficiently as cattle have ability to learn quickly how to move through facilities and cope with changing environments when managed by competent handlers [15].

\subsection{Meat Distribution and Meat Safety Issues}

It was observed that most of butchers were willing to buy animals without much worry about the health status of the animals. In addition to this it was learnt that none of these butchers used approved meat vans to transport the meat from abattoir to their shops (see Figure 1). This means that there is a serious public health concern, since the meat meant for public consumption in Kumasi sometimes sourced from sick animals and the meat is always transported in unhygienic vehicles. In the current study, animals were not allowed to rest in most cases during transport from origin to Kumasi cattle market. This long journey without rest puts physical fatigue on the animals which are transported from long distances to Kumasi cattle market. According to Immonen [16], physical stress by hunger, fatigue, lesions, besides the physiological stress, can lead to depletion of muscle glycogen reserves and propitiate the incidence of dark, firm and dry (DFD) meat. Detailed study concerning the impact of poor animal transport system on animal welfare, meat safety and quality and the consequent impact on human health will be conducted as continued part of this project. 


\section{Conclusions}

In this study the main characteristics of the animal supply to the Kumasi abattoir and activities in the abattoir chain were mapped out. The main stakeholders involved were farmers, merchants, landlords and butchers. The cattle transported to the Kumasi Abattoir were purchased from individual farmers' farms, regional markets, and big markets in Burkina Faso, Cote D'Ivoire, Ghana (Northern Ghana and Yeji in the Brong Region of Ghana), Mali and Niger. The purchased animals were then sent to a collection centre in those countries before onward transportation to the Cattle Market in the Kumasi city. From the market the cattle are moved into the abattoir for slaughter and the meat is then sent to the butcheries where it is being sold.

This study indicated that inhuman way of animal handling, incidence of non-ambulation and death of animals were common due to poor loading and unloading procedures, overcrowding and falling on the truck, hunger, disease, and unfavorable weather the animals were exposed to during transport and inside Kumasi cattle market. Only during the transport from source to Kumasi, more than $16 \%$ of expected revenue was lost due to inappropriate animal handling. The poor hygienic conditions of the slaughtering procedures and meat distribution to the butcheries using unhygienic vehicles disclosed the existing problems concerning the safety and quality of meat. These issues of animal welfare and meat safety and quality should get attention and further studies should be carried out and improvements must be planned by the concerning bodies.

\section{REFERENCES}

[1] D. Fraser, "Toward a Global Perspective on Farm Animal Welfare," Applied Animal Behavioral Science, Vol. 113, No. 4, 2008, pp. 330-339. doi:10.1016/j.applanim.2008.01.011

[2] G. Gebresenbet, D. Ljunberg, R. Geers and G. Van de Water, "Effective Logistics to Improve Animal Welfare in the Production Chain, with Special Emphasis on FarmAbattoir System," International Society for Animal Hygiene, Vol. 1, 2004, pp. 37-38.

[3] K. J. Southern, J. G. Rasekh, F. E. Hemphill and A. M. Thaler, "Conditions of Transfer and Quality of Food," Scientific and Technical Review of the Office International des Epizooties, Vol. 25, No. 2, 2006, pp. 675-684.

[4] M. K. Edge and J. L. Barnett, "Development of Animal Welfare Standards for the Livestock Transport Industry: Process, Challenges, and Implementation," Journal of Veterinary Behavioral, Vol. 4, No. 5, 2009, pp. 187-192. doi:10.1016/j.jveb.2009.07.001
[5] G. Gebresenbet, "Farm Animal Welfare during Transport. E.C Report on Farm Animal Welfare Current Research and Future Directions," 2003.

http://ec.europa.eu/research/agriculture/pdf/animal-welfar e_en.pdf

[6] D. Ljungberg, G. Gebresenbet and S. Aradom, "Logistics Chain of Animal Transport and Abattoir Operations," Biosystems Engineering, Vol. 96, No. 2, 2007, pp. 267277. doi:10.1016/j.biosystemseng.2006.11.003

[7] G. Gebresenbet, T. G. Bosona, D. Ljungberg and S. Aradom, "Optimisation Analysis of Large and Small-Scale Abattoirs in Relation to Animal Transport and Meat Distribution," Australian Journal of Agricultural Engineering, Vol. 2, No. 2, 2011, pp. 31-39.

[8] V. Deiss, D. Temple, S. Ligout, C. Racine, J. Bouix, C. Terlouw and A. Boissy, "Can Emotional Reactivity Predict Stress Responses at Slaughter in Sheep?" Applied Animal Behavioral Science, Vol. 119, No. 3-4, 2009, pp. 193-202. doi:10.1016/j.applanim.2009.03.018

[9] M. Malena, E. Voslářova, P. Tomanová, R. Lepková, I. Bedáňová and V. Večerek, "Influence of Travel Distance and Season upon Transport-Induced Mortality in Fattened cattle," Acta Veterinaria Brno, Vol. 75, No. 4, 2006, pp. 619-624. doi:10.2754/avb200675040619

[10] J. Reynolds, "Dealing with Downers," The AABP proceedings, Vol. 39, 2006, pp. 28-31. http://ansci.colostate.edu/files/dairy_news/v13_4/Downer s.pdf

[11] V. S. Cox, W. E. Marsh and G. R. Steurnagel, "Downer Cow Occurrence in Minnesota Dairy Herds," Preventive Veterinary Medicine, Vol. 4, 1986, pp. 249-260. doi:10.1016/0167-5877(86)90027-9

[12] L. S. Carolyn, M. A. Payne, S. L. Berry and J. P. Reynolds, "A Review of the Causes, Prevention, and Welfare of Non-Ambulatory Cattle," Veterinary Medicine Today: Reference Point, Vol. 231, No. 2, 2007, pp. 227-234.

[13] D. M. Broom, "The Effects of Land Transport on Animal Welfare," Scientific and Technical Review of the Office International des Epizooties, Vol. 24 No. 2, 2005, pp. 683-691.

[14] G. Gebresenbet, "Farm Animal Welfare during Transport," E.C Report on Farm Animal Welfare Current Research and Future Directions, 2002.

http://ec.europa.eu/research/agriculture/pdf/animal-welfar e_en.pdf

[15] S. Atkinson, "The Importance of Animal Handling Technique and Animal Handling Facility Design for the Welfare of Slaughter Animals," NJF Report, Vol. 1, No. 4. 2005.

http:/www.njf.nu/filebank/files/20060904\$211818\$fil\$T eQq2b6EMZ55RzFnx4YL.pdf

[16] K. Immonen, M. Ruusunen and E. Puolanne, "Some Effects of Residual Glycogen Concentration on the Physical Sensory Quality of Normal Ph Beef," Meat Science, Vol. 55, No. 1, 2000, pp. 33-38. doi:10.1016/S0309-1740(99)00122-9 